\title{
Enfekte implant revizyonu: DAiR (Debridman, Antibiyotik ve İmplant Retansiyonu) -tek aşamalı revizyon artroplastisi
}

\author{
Revision of infected implant: DAIR (Debridement, Antibiotics and \\ Implant Retention) -one stage revision arthroplasty
}

\author{
İsmail Remzi Tözün, Vahit Emre Özden, Göksel Dikmen, Kayahan Karaytuğ \\ Acıbadem Mehmet Ali Aydınlar Üniversitesi, Ortopedi ve Travmatoloji Anabilim Dalı, \\ Acıbadem Maslak Hastanesi Ortopedi ve Travmatoloji Kliniği, İstanbul
}

\begin{abstract}
Protez çevresi eklem enfeksiyonları (PEE), güncel kılavuzlara göre erken-akut, gecikmiş-kronik, geç-akut hematojen ve geç-kronik PEE olarak sınıflandırılmaktadır. PEE'de tedavi seçenekleri debridman, antibiyotik ve implant retansiyonu (DAiR), tek veya iki aşamalı revizyon artroplastisidir. Kurtarıcı girişimler ise rezeksiyon artroplastisi, artrodez ve diz üstü amputasyon olarak sıralanabilir. Akut PEE'de ilk önerilen cerrahi yöntem DAiR'dir. DAIR, klinik olarak şüphe duyulan olgularda ilk üç hafta (özellikle ilk 7-10 gün) içinde yapılmalıdır. DAiR öncesinde hastaların KLIC ve CRIME anketleri ile değerlendirilmesi ameliyat sonrası dönemde elde edilecek tedavi etkinliğini belirlemede yol göstericidir. Etken mikroorganizmanın ameliyat öncesi dönemde izole edilmesi ve antibiyotik duyarlılığının belirlenmesi ise başarı oranlarını artıran en önemli faktördür. Subakut ve kronik enfeksiyonlarda bakteriyel biyofilm tabakası oluşumu nedeni ile revizyon artroplasti seçenekleri ilk tercih olarak düşünülmelidir. PEE'lerin cerrahi tedavisinde halen altın standart yöntem iki aşamalı revizyon artroplastisi olmakla birlikte tek aşamalı revizyon artroplasti uygulaması gittikçe artan sıklıkta tercih edilen bir yöntem haline gelmiştir. Tek aşamalı revizyon artroplasti uygulamasında başarılı sonuçlar için dikkat edilmesi gereken kriterler; hastanın bağışıklık sisteminin kuvvetli olması, sepsisin olmaması, primer yara kapatılmasına izin veren yeterli yumuşak doku varlığı ile kemik kaybının minimal seviyede olması ve en önemlisi etken mikroorganizmanın operasyon öncesinde tespit edilmesidir.
\end{abstract}

Anahtar sözcülkler: periprostetik eklem enfeksiyonu; tek seaslı revizyon artroplastisi; PIJ; DAIR
Periprosthetic joint infections (PJI) are classified as earlyacute, delayed-chronic, late-acute and late-chronic hematogenous PJI according to current guidelines. Treatment options in PJI are debridement, antibiotics and implant retention (DAIR), single or two-stage revision arthroplasty. Sal-vage procedures are resection arthroplasty, arthrodesis, and above-knee amputation. In acute PJI, the first recommended surgical method is DAIR. DAIR should be done within the first 3 weeks (especially first 7-10 days) in clinically suspected cases. Evaluation of the patients before DAIR with KLIC and CRIME questionnaire guides the effectiveness of the treatment in the postoperative period. Isolation of the causative microorganism in the preoperative period and determination of antibiotic sensitivity is the most important factor that increases the success rates. In subacute and chronic infections due to the formation of a bacterial biofilm layer, revision arthroplasty op-tions should be considered as a first choice. Although still two-stage revision arthroplasty is the gold standard, single-stage revision arthroplasty is gradually becoming a preferred method. In single-stage revision arthroplasty the criteria for successful results; resistant immune system, lack of systemic sepsis, enough soft tissue that provides primary wound coverage, minimal bone loss, first and for most the detection of the causative microorganism before the operation.

Key words: periprosthetic joint infections; single-stage revision arthroplasty; PJI; DAIR

enfeksiyon bulgularının ortaya çıkmasına kadar geçen süreye göre, erken-akut, gecikmiş-kronik, geç akut hematojen ve geç-kronik PEE olarak sınıflandırılmıştır (Tablo 1). PEE tedavi yönetimi farklı cerrahi teknikler ve hedefe uygun antimikrobiyal tedaviler içerir (Şekil 1). ${ }^{[5-7]}$

- Illetişim adresi: Prof. Dr. İsmail Remzi Tözün, Fulya Mah. Hakkı Yeten Cad. 19, Unimed İş Mrk. K:6, Şişli, İstanbul

Tel: 0542 - 4242664 e-posta: rtozun@gmail.com

- Geliș tarihi: 31 Mayıs $2020 \quad$ Kabul tarihi: 29 Haziran 2020 
Tablo 1. Protez çevresi eklem enfeksiyonlarının zamana göre sınıflaması ve olası klinik bulgular ${ }^{[8]}$

\begin{tabular}{|c|c|c|c|c|}
\hline Enfeksiyon tipi & $\begin{array}{l}\text { Klinik belirtilerin } \\
\text { başlangıcı }\end{array}$ & $\begin{array}{l}\text { Enfeksiyon } \\
\text { mekanizması }\end{array}$ & Organizma & Klinik belirtiler \\
\hline Erken & $<3$ ay & $\begin{array}{l}\text { Ameliyat sırasında } \\
\text { kontaminasyon }\end{array}$ & $\begin{array}{l}\text { Virulan bakteri } \\
\text { (sıklıkla S.aureus) }\end{array}$ & $\begin{array}{l}\text { Akut; ani gelişen eritem, ödem, ısı artışı ve } \\
\text { hassasiyet }\end{array}$ \\
\hline Gecikmiş & 3-12 ay & $\begin{array}{l}\text { Ameliyat sırasında } \\
\text { kontaminasyon }\end{array}$ & $\begin{array}{l}\text { Düşük virulanslı bakteriler } \\
\text { (koagülaz-negatif stafilokok) }\end{array}$ & Kronik; eklem ağrısı, eklem sertliği \\
\hline Geç & $>12$ ay & $\begin{array}{l}\text { Hematojen } \\
\text { yayılım } \\
\text { Ameliyat sırasında } \\
\text { kontaminasyon }\end{array}$ & $\begin{array}{l}\text { Virulan bakteri } \\
\text { (sıklıkla S.aureus) } \\
\text { Düşük virülanslı bakteriler } \\
\text { (koagülaz-negatif stafilokok) }\end{array}$ & $\begin{array}{l}\text { Akut; ani gelişen eritem, ödem, ısı artışı ve } \\
\text { hassasiyet } \\
\text { Kronik; eklem ağrısı, fistül mevcudiyeti }\end{array}$ \\
\hline
\end{tabular}

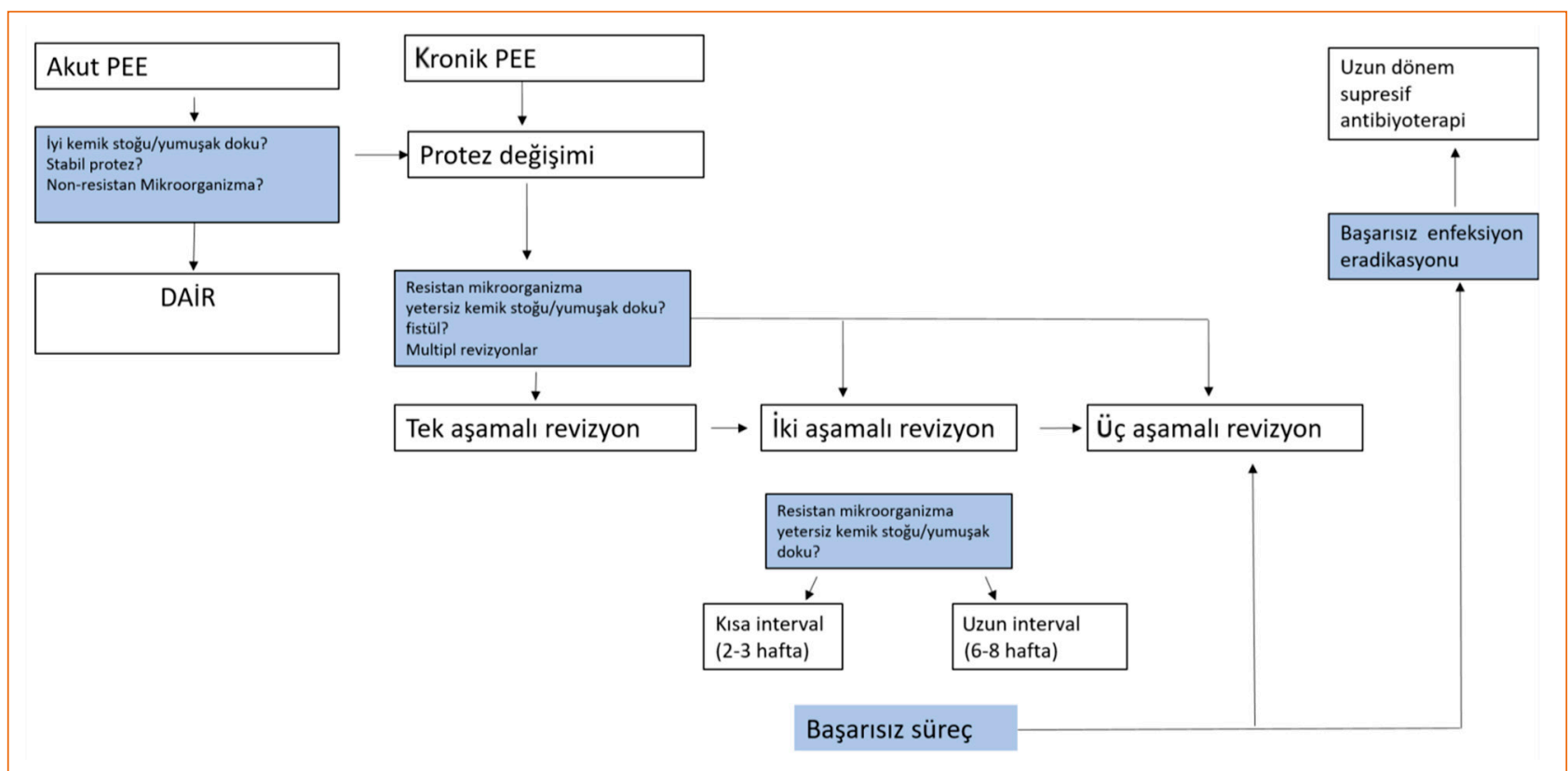

Şekil 1. PEE için tedavi algoritması. (PEE Tanı ve Tedavisi için Yeniden basılmış Cep Rehberi [Sürüm 9, Ekim 2019]. PRO-ıMPLANT Vakfi'nın izniyle [www.pro-implant-foundation.org])

Erken-akut PEE, TEA sonrası ilk 3-12 haftalık süreyi içerir. Geç-akut hematojen enfeksiyon varlığında semptomların görülmesinden sonraki 10 gün ile üç haftalık zaman dilimini içerir. Gecikmiş PEE cerrahiden 3-12 ay sonrası, geç ise 12 aydan sonra gelişen PEE olarak tanımlanır. ${ }^{[8]}$ Erken ve geç PEE arasındaki birincil zaman ayrımı, bileşenlerin yüzeyindeki biyofilm oluşumuna dayanır. Ancak, biyofilm oluşumu birkaç saatten birkaç güne kadar herhangi bir zamanda ortaya çıkabilir. ${ }^{[9,10]}$

Uluslararası Konsensus Toplantısı (ICM-2018), PEE'nin tanımı için onaylanmış, kanıta dayalı yeni bir puanlama sistemi önermiştir. ${ }^{[11]}$ PEE cerrahi tedavi seçenekleri arasında kesin olarak doğrulanmış bir ayrım yoktur. Tedavide debridman, antibiyotik ve implant retansiyonu (DAiR), bir veya iki aşamalı revizyon artroplasti girişimleri sayılabilir. Bu tedaviler yetersiz olduğunda, rezeksiyon artroplastisi, artrodez ve diz üstü amputasyon gibi kurtarma girişimleri gibi farklı cerrahi yöntemler bulunmaktadır (Tablo 2). ${ }^{[1]}$

\section{DEBRIDMAN, ANTIBIYOTIK VE IMPLANT KORUMA (DAIR)}

Debridman, antibiyotik tedavisi ve implantı koruma-retansiyonu (DAiR), dört haftadan kısa sürede ortaya çıkan erken ameliyat sonrası enfeksiyonlarda veya üç haftadan kısa semptom süresi olan akut hematojen enfeksiyonlarda kullanılan, daha az morbid 
Tablo 2. Olası senaryolarla cerrahi stratejilere genel bakış ${ }^{[1]}$

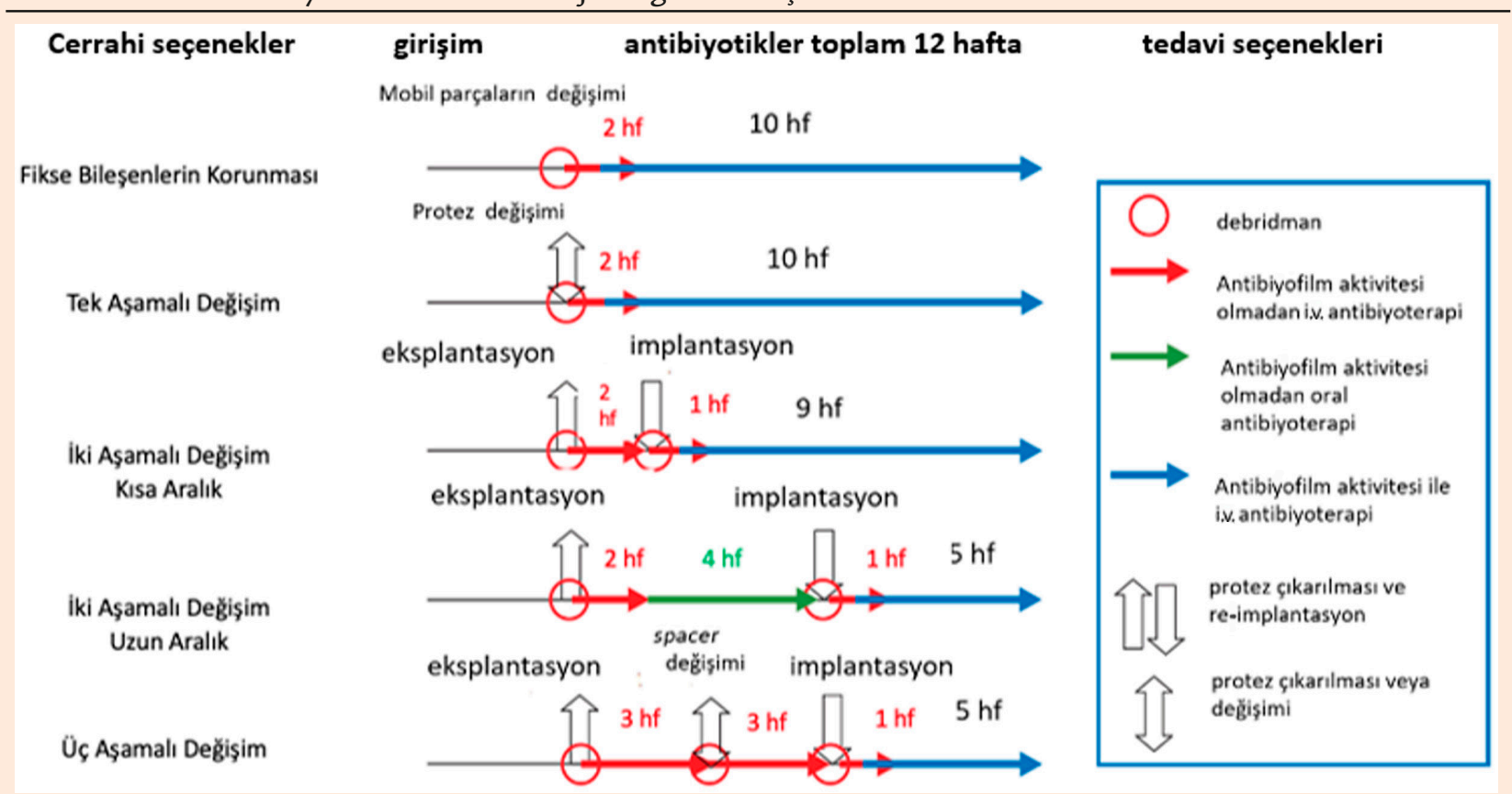

PEE Tanı ve Tedavisi için Yeniden basılmış Cep Rehberi (Sürüm 9, Ekim 2019). (PRO-IMPLANT Vakfínın izniyle [www.pro-implant-foundation.org])

ve protezi koruyan bir cerrahi yöntemdir. Bazı yazarlar akut hematojen enfeksiyon varlığında DAiR'in ilk 7-10 gün içinde yapılmasının daha etkili olacağını bildirmektedir. ${ }^{[12]}$ DAIR, fonksiyonel bir hastada stabil olan implantları korumayı amaçlar. Farklı çalışmalarda DAiR ile ilgili farklı başarı oranları (\%16-82) bildirilmiştir (Şekil 2). ${ }^{[13-15]}$

Kronik PEE'ler DAIR için mutlak bir kontrendikasyon olarak düşünülmelidir. Kronik enfeksiyonlarda DAiR'nin başarı oranı yaklaşık \%50'dir. Metisiline dirençli stafilokok enfeksiyonu varlığı, semptomların süresinin dört haftaya ulaşması başarısızlık ihtimalini belirgin şekilde artırmaktadır. ${ }^{[16-18]}$

Akut PEE'de DAIR uygulanmasına yönelik kontrendikasyonlar tartışmalıdır. Akut PEE'de DAIR'nin başarısı büyük ölçüde bakteriyel mikroorganizmaların ameliyat öncesi dönemde izole edilmesi ve antibiyotik duyarlılığının tespitine bağlıdır. Birçok geriye dönük çalışmada, DAiR sonuçlarını etkileyen konağa ve implanta bağı faktörler, ameliyat sırasında değişkenler, enfeksiyona neden olan organizmanın antibiyotik duyarlılığı gibi çoğu etken değerlendirilmiştir. ${ }^{[15,19,20]}$ DAiR planlanan hastalarda, ameliyat sonrası muhtemel başarı düzeyini öngörebilmek amacı ile akut böbrek yetmezliği, karaciğer sirozu, indeks cerrahisi, çimentolu protez ve
C-reaktif protein değerlerinin incelendiği KLIC skoru ve akut hematojen PEE skorlama anketi olan CRIME80 skoru kullanılmaktadır (Şekil 3). ${ }^{[21,22]}$

Bu yöntemde agresif debridman ve modüler parçaların değişimi yapılmalıdır. DAiR sırasında modüler parçaların değiştirilmemesi yüksek başarısızlık oranları ile ilişkilendirilmiştir. ${ }^{[15,23,24]}$ Uluslararası Konsensus Grubu, irrigasyon ve debridman sırasında, intra-artiküler uygulanan metilen mavisi kılavuzluğunda yapılan agresif debridman ile enfekte olduğu düşünülen bütün dokuların, iyi kanamayan kemiklerin ve yumuşak dokuların uzaklaştırılmasını önermektedir. ${ }^{[25]}$ Yeterli debridman sonrası artmış vasküler dolaşım, bağışıklık sistemini güçlendirmekte ve periartiküler dokulara antibiyotik penetrasyonunu artırmaktadır. ${ }^{[26,27]}$ Literatür, debridman sırasında yaklaşık dokuz litre irrigasyon çözeltisinin yeterli olduğunu göstermektedir. ${ }^{[28]}$ Bu hacim, cerrahi alanın büyüklüğüne ve enfeksiyonun şiddetine bağlı olarak artırılabilir. Ancak yıkama basıncı tartışmalı bir konudur. Bazı yazarlar düşük basınçlı (inç kare başına $<15$ pound) lavaj tekniğini desteklerken, diğerleri yüksek basınçlı yöntemi (inç kare başına $>45$ pound) savunmaktadırlar. ${ }^{[1,28,29]}$ Yüksek basınçlı yıkama, enfektif nekrotik dokuların sahadan uzaklaştırılmasını sağlar, ancak enfektif partiküllerin derin dokuları kontamine edebileceği akılda tutulmalıdır. 

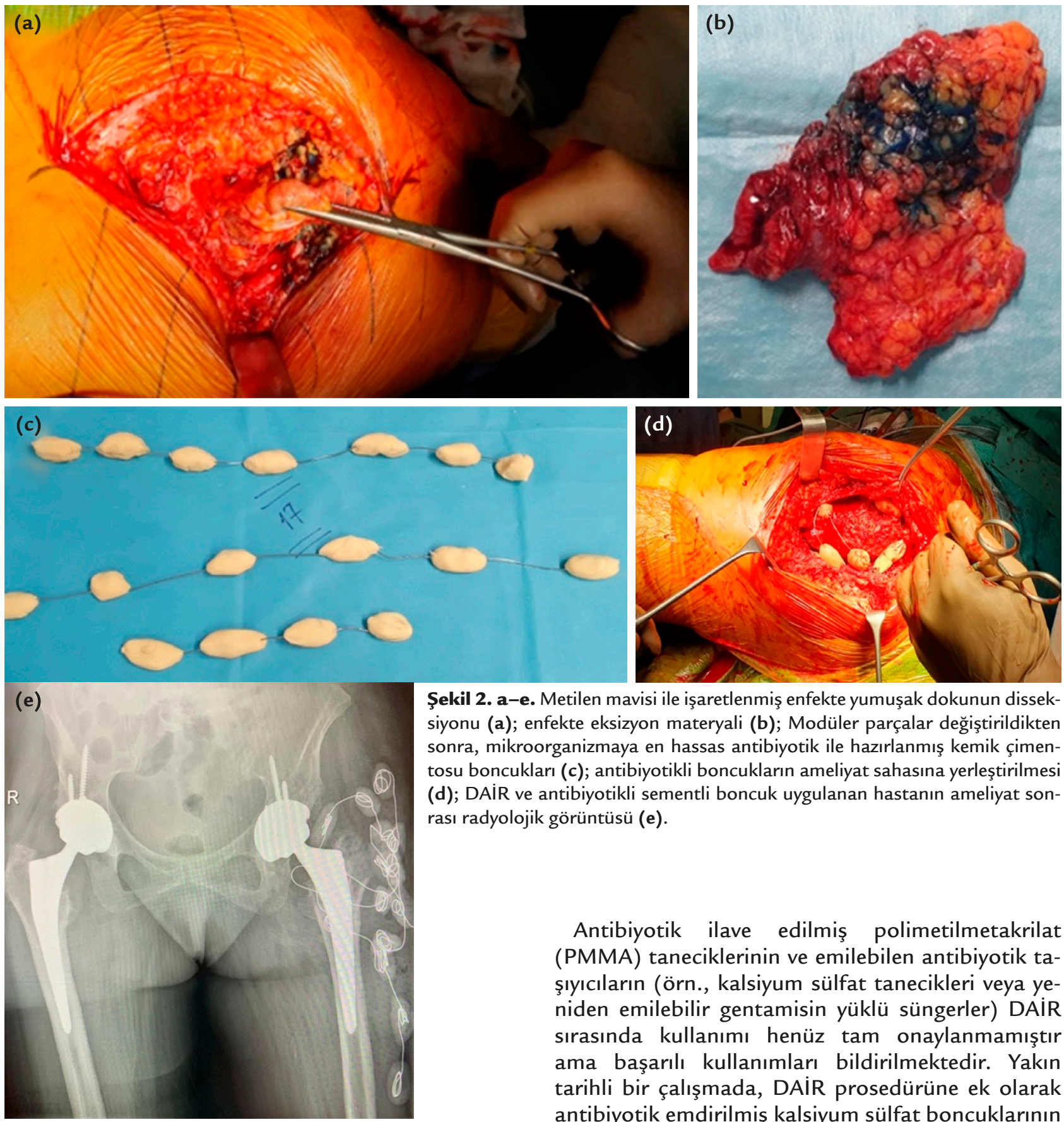

İrrigasyon ve debridmandan sonraki ilk ve en önemli aşama hastaya kombine intravenöz antibiyotik tedavisi uygulanmasıdır. Antibiyotik tedavisi cerrahi sonrası en az 4-6 hafta sürmelidir ve ek olarak altı aya kadar oral rifampisin verilmesi önerilmektedir. ${ }^{[1,5,30]}$ Bununla birlikte, uzun süreli antibiyotik tedavisinin, enfeksiyonu sadece baskılayacağı fakat ortadan kaldıramayacağı da gösterilmiştir. ${ }^{[31]}$
Şekil 2. a-e. Metilen mavisi ile işaretlenmiş enfekte yumuşak dokunun disseksiyonu (a); enfekte eksizyon materyali (b); Modüler parçalar değiştirildikten sonra, mikroorganizmaya en hassas antibiyotik ile hazırlanmış kemik çimentosu boncukları (c); antibiyotikli boncukların ameliyat sahasına yerleştirilmesi (d); DAIR ve antibiyotikli sementli boncuk uygulanan hastanın ameliyat sonrası radyolojik görüntüsü (e).

Antibiyotik ilave edilmiş polimetilmetakrilat (PMMA) taneciklerinin ve emilebilen antibiyotik taşıyıcıların (örn., kalsiyum sülfat tanecikleri veya yeniden emilebilir gentamisin yüklü süngerler) DAiR sırasında kullanımı henüz tam onaylanmamıştır ama başarılı kullanımları bildirilmektedir. Yakın tarihli bir çalışmada, DAiR prosedürüne ek olarak antibiyotik emdirilmiş kalsiyum sülfat boncuklarının kullanımının (DAPRI), revizyon cerrahisindeki başarılı sonuçları bildirilmiştir. ${ }^{[12]}$ DAiR'de tatmin edici sonuçlar elde edebilmek için temiz kanamalı dokulara ulaşmamızı sağlayacak kadar geniş ve etkili bir debridman yapmak, modüler parçaları değiş̧tirmek ve enfeksiyon ajanına en uygun antibiyotiği seçmek zorunludur.

Başarısız bir DAiR'nin ardından yapılması planlanan tek veya iki seanslı revizyon artroplastisinin başarısını olumsuz etkileyebileceği konusu hala tartışmalıdır. Başarısız bir DAiR'nin aşamalı tedavinin 

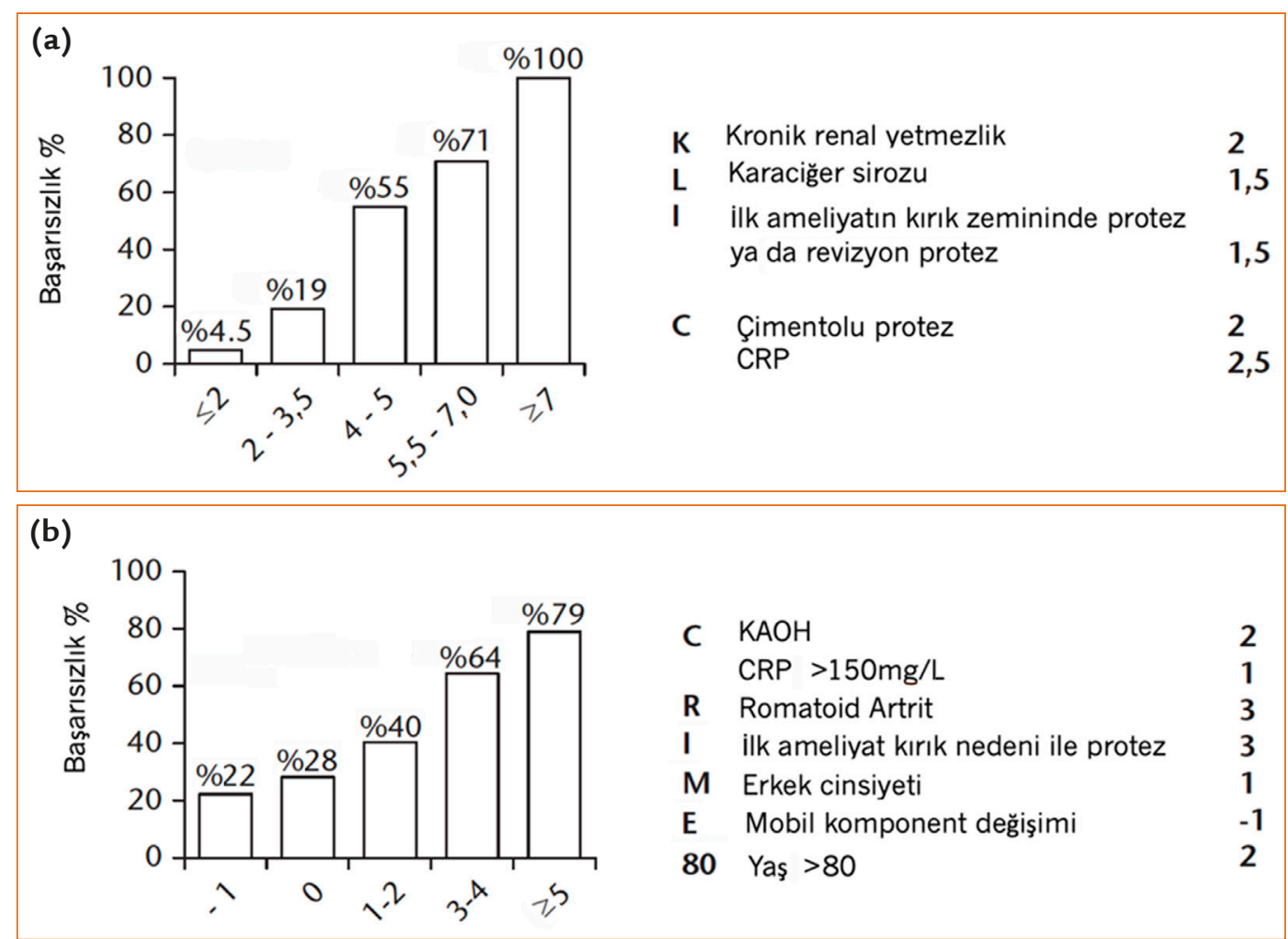

Şekil 3. a, b. KLIC (a) ve CRIME80 (b) skorlamaları. ${ }^{[20,21]}$

başarı şansını azalttığını gösteren çalışmalar da mevcut olmakla beraber ${ }^{[2-34]}$ enfeksiyon tipine dayalı alt grup analizi içeren çok merkezli güncel geriye dönük bir çalışmada, başarısız DAIR sonrası yapılan aşamalı artroplati sonuçları ile DAIR olmadan yapılan aşamalı artroplasti sonuçları arasında istatistiksel olarak anlamlı bir fark bulunmamıştır. (DAiR sonrası $\% 72$ ve DAiR olmadan \%81). ${ }^{[35]}$

\section{TEK AŞAMALI REVIZYON ARTROPLASTISi}

Tek aşamalı revizyon artroplastisi, seçilmiş olgular başta olmak üzere PEE tedavisinde tercih edilme sıklığı giderek artan bir yöntem olarak karşımıza çıkmaktadır. Bu uygulamanın daha az morbidite, daha iyi fonksiyonel sonuç, daha az yatışı süresi ve daha az maliyetli olması gibi birçok avantaja sahip olduğu bildirilmiştir. ${ }^{[36,37]}$

PEE tedavisinde altın standart tedavi olarak kabul gören iki aşamalı revizyon cerrahisinin, tek aşamalı revizyon cerrahisine göre kanıta dayalı kesin bir üstünlügüu yoktur. Tek aşamalı revizyon artroplastisinin başarı oranları \%75 ile \%95 arasında değişmektedir. ${ }^{[37,38]}$ Tek aşamalı girişimin yüksek başarı oranı, hasta seçim kriterleri ve hastaya özel ameliyat öncesi planlama protokolleri ile sıkı bağlantılıdır. Ameliyat öncesinde enfeksiyona neden olan mikroorganizmanın belirlenmesi tek aşamalı revizyon cerrahisi için zorunludur. Ameliyat öncesi etken mikroorganizmanın belirlenmesi lokal ve sistemik antibiyotik kullanımında etkili olacaktır. Uluslararası Konsensus Komitesince (ICM-2018) tek aşamalı revizyon artroplastisi, sepsis, ağır komorbidite, dirençli organizma enfeksiyonları, kültür negatif enfeksiyonlar ve zayıf yumuşak doku örtüsü olan hastalar için iyi bir seçenek olmayabileceği bildirilmiştir. ${ }^{[39]}$

Tek Aşamalı Revizyon Artroplastisi için Endikasyonları (ICM 2018) ${ }^{[39]}$

\section{Hastaya ait}

- İmmunosupresif olmaması

- Sepsisin olmaması

- Primer yara kapanmasına izin veren minimal kemik kaybı/yumuşak doku defekti

\section{Mikrobiyolojik açıdan}

- Patojenin izolasyonu

- Bakterisidal tedaviye hassas patojen saptanması 

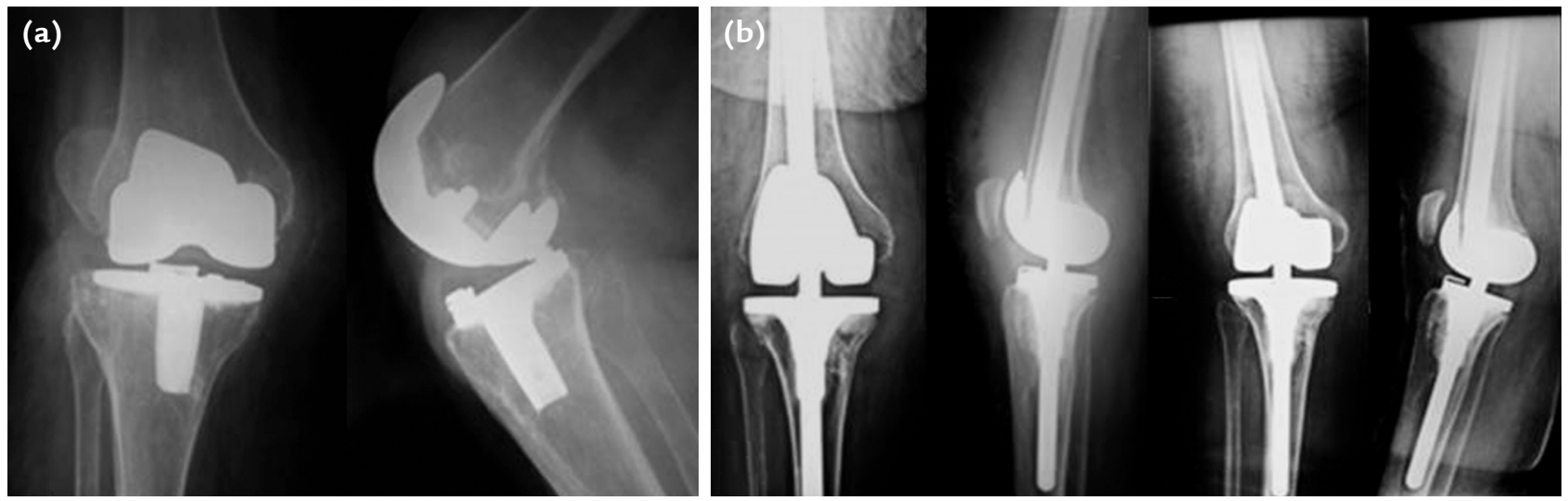

Şekil 4. a, b. Sağ total diz eklem artroplastisi uygulama sonrası 2. yılında PEE gelişmiş ve etken organizma E.coli üretilmiş olan hastanın sağ diz radyografik görüntüsü (a). Etken mikroorganizmaya uygun antibiyotik, kemik çimentosu içerisine ilave edilerek tek aşamalı revizyon artroplastisi uygulanan hastanın erken ve ameliyat sonrası 2. yıl radyografik görüntüleri (b).

\section{Tek Aşamalı Revizyon Artroplastisi için Göreceli Kontrendikasyonlar (ICM 2018) ${ }^{[39]}$}

Uluslararası Konsensus komitesince tek aşamalı revizyon artroplastisinin göreceli kontrendike olduğu durumlar şunlardır:

- Eklem ve yaranın doğrudan kapanmasının mümkün olmadığı ciddi yumuşak doku kaybı veya eski skarla birlikte eksize edilemeyen kompleks sinus traktı.

- Etken organizmanın veya duyarlılığının bilinmediği kültür negatif PEE.

- Enfekte yumuşak doku veya kemiğin radikal debridmanının mümkün olmadığı durumlar (herhangi bir nedenle).

- Lokal antimikrobiyal tedavinin mümkün olamadığı durumlar.

- Yeniden implantasyon için yetersiz kemik stoğu olması.

Tek aşamalı revizyon artroplastisinde, ilk adımda geniş debridman yapılması zorunludur. Bu debridmanda eklem çevresi yumuşak dokularda ve kemikte iyi kanlanan bölgelere ulaşılması amaçlanmalıdır. Tüm membranlar, kemiğe sıkıca adapte olmuş çimento partikülleri ve özellikle arka kapsül debride edilmelidir. Dedridman, tüm osteoliz alanları ve nekrotik kemikleri içerecek şekilde, geniş ve radikal olmalıdır. Sıkı tutunmuş çimento ve bileşenlerin çıkarılması sırasında, kemiği korumak için yüksek hızı kazıyıcı aletler (burr), esnek testere bıçakları, eğri osteotomlar, uzun rongeur'lar, küretaj aletleri, uzun matkaplar, oluklu osteotomlar ve Gigli testere gibi bazı özel cerrahi aletler gerekebilir. Tüm periartiküler alanlardan, özellikle tibial, femoral intramedüller kanallardan ve arka kapsülden mikrobiyolojik değerlendirme için çoklu örnekler alınmalıdır. Girişim boyunca pulsatil lavaj tavsiye edilir, ancak literatürde belirli bir yararı olup olmadığı yönünde kesin kanıt yoktur. ${ }^{[29]}$ İrrigasyon sonrası, antiseptik çözeltilere sahip gazlı bezler (povidon-iyot, klorheksidin, vb.) intramedüller bölgeye ve eklem içerisine eklemi tamamen dolduracak biçimde paketlenir ve yara kenarları tamamen kapatılır. 30-45 dakikalık bekleme süresi sonunda, tek aşamalı girişimin ikinci adımı için ameliyat ekibi yeni bir ameliyata başlıyormuş gibi yıkanır ve giyinir, hastayı yeni steril ameliyat örtüleri ile tekrar örter ve yeni cerrahi setler ile ameliyatın ikinci aşamasını gerçekleştirir. ${ }^{[40,41]}$ Re-implantasyonda, patojen mikroba hassas antibiyotiğin çimentoya eklenmesi ve ameliyat sonrası dönemde duyarlı antibiyotik tedavilerinin uygulanması başarı için önemlidir (Şekil 4). ${ }^{[42]}$ Yakın döneme ait sistemik derlemede, seçilmiş hastalarda, tek aşamalı revizyona ait çok başarılı sonuçlar bildirilmiştir. ${ }^{[43]}$ Kalça ve diz total eklem artroplastisi sonrası PEE gelişen hastalarda, tek ve iki aşamalı revizyon artroplastisi sonuçlarını, ayrı ayrı karşılaştıran yakın döneme ait iki meta-analizde, her iki protokol için istatistiksel olarak eşdeğer re-enfeksiyon oranları gösterilmiştir. ${ }^{[44,45]}$

\section{KAYNAKLAR}

1. Gehrke T, Alijanipour P, Parvizi J. The management of an infected total knee arthroplasty. Bone Joint J 2015;97-B(10_ Supple_A):20-9. Crossref

2. Bozic KJ, Kurtz SM, Lau E, Ong K, Chiu V, Vail TP, Rubash HE, Berry DJ. The epidemiology of revision total knee arthroplasty in the United States. Clin Orthop Relat Res 2010;468:45-51. Crossref

3. Kurtz SM, Lau E, Schmier J, Ong KL, Zhao K, Parvizi J. Infection burden for hip and knee arthroplasty in the United States. J Arthroplasty 2008;23(7):984-91. Crossref

4. Kurtz SM, Ong KL, Lau E, Bozic KJ, Berry D, Parvizi J. Prosthetic joint infection risk after TKA in the Medicare population. Clin Orthop Relat Res 2010;468(1):52-6. Crossref 
5. Osmon DR, Berbari EF, Berendt AR, Lew D, Zimmerli W, Steckelberg JM, Rao N, Hanssen A, Wilson WR. Executive summary: diagnosis and management of prosthetic joint infection: clinical practice guidelines by the Infectious Diseases Society of America. Clin Infect Dis 2013;56(1):1-10. Crossref

6. Della Valle C, Parvizi J, Bauer TW, DiCesare PE, Evans RP, Segreti J, Spangehl M, Watters WC, Keith M, Turkelson CM, Wies JL, Sluka P, Hitchcock K. American Academy of Orthopaedic Surgeons clinical practice guideline on: the diagnosis of periprosthetic joint infections of the hip and knee. J Bone Joint Surg Am 2011;93(14):1355-7. Crossref

7. Zmistowski B, Della Valle C, BauerTW, Malizos KN. Diagnosis of periprosthetic joint infection. J Orthop Res 2014;32(Suppl 1):S98-107. Crossref

8. Gomez-Urena EO, Tande AJ, Osmon DR, Berbari EF. Diagnosis of prosthetic joint infection: cultures, biomarker and criteria. Infect Dis Clin North Am 2017;31(2):219-35. Crossref

9. Donlan RM. Biofilms: microbial life on surfaces. Emerg Infect Dis 2002;8(9):881-90. Crossref

10. Gbejuade $\mathrm{HO}$, Lovering AM, Webb JC. The role of microbial biofilms in prosthetic joint infections. Acta Orthop 2015;86(2):147-58. Crossref

11. Parvizi J, Tan TL, Goswami $K$, Higuera C, Valle CD, Chen AF, Shohat N. The 2018 Definition of Periprosthetic Hip and Knee Infection: An Evidence-Based and Validated Criteria. J Arthroplasty 2018;33(5):1309-14. Crossref

12. Calanna F, Chen F, Risitano S, Vorhies JS, Franceschini M, Giori $\mathrm{NJ}$, Indelli PF. Debridement, antibiotic pearls, and retention of the implant (DAPRI): A modified technique for implant retention in total knee arthroplasty PJI treatment. J Orthop Surg (Hong Kong) 2019;27(3):2309499019874413. Crossref

13. Bradbury T, Fehring TK, Taunton M, Hanssen A, Azzam K, Parvizi J, Odum SM. The fate of acute methicillin-resistant Staphylococcus aureus periprosthetic knee infections treated by open debridement and retention of components. J Arthroplasty 2009;24(6):101-4. Crossref

14. Urish KL, Bullock AG, Kreger AM, Shah NB, Jeong $K$, Rothenberger SD, Irrgang JJ, Klatt BA, Hamlin BR. A Multicenter Study of Irrigation and Debridement in Total Knee Arthroplasty Periprosthetic Joint Infection: Treatment Failure Is High. J Arthroplasty 2018;33(4):1154-9. Crossref

15. Tsang SJ, Ting J, Simpson A, Gaston P. Outcomes following debridement, antibiotics and implant retention in the management of periprosthetic infections of the hip: a review of cohort studies. Bone Joint J 2017;99-B(11):1458-66. Crossref

16. Barberan J, Aguilar L, Carroquino G, Giménez MJ, Sánchez B, Martínez D, Prieto J. Conservative treatment of staphylococcal prosthetic joint infections in elderly patients. Am J Med 2006;119(11):993.e7-10. Crossref

17. Maillet M, Pavese P, Bruley D, Seigneurin A, François P. Is prosthesis retention effective for chronic infections in hip arthroplasties? A systematic literature review. Eur J Clin Microbiol Infect Dis 2015;34:1495-502. Crossref

18. Lora-Tamayo J, Murillo O, Iribarren JA, Soriano A, SánchezSomolinos M, Baraia-Etxaburu JM, Rico A, Palomino J, RodríguezPardo D, Horcajada JP, Benito N, Bahamonde A, Granados A, Dolores del Toro M, Cobo J, Riera M, Ramos A, Jover-Sáenz A, Ariza J, Euba G, Cabo X, Pedrero S, Goenaga MÁ, Elola M, Moreno E, García-Ramiro S, Martínez-Pastor JC, Tornero E, García-Lechuz JM, Marín M, Villanueva M, López I, Cisterna R, Santamaría JM, Gómez MJ, Puente A, Cano P, Pigrau C, Sordé R, Flores X, Sorlí L, González-Miguez P, Puig L, Franco M, Jordán M, Coll P, AmadorMellado J, Fuster-Foz C, García-Paíno L, Nieto I, Muniain MÁ, Suárez Al, Maseguer MA, Garagorri E, Pintado V, Marinescu C, Ramírez A, Múñez E, Álvarez T, García R, Barcenilla F, Prat L,
Pérez F; REIPI Group for the Study of Prosthetic Infection. A large multicenter study of methicillin-susceptible and methicillin-resistant Staphylococcus aureus prosthetic joint infections managed with implant retention. Clin Infect Dis 2013;56(2):182-94. Crossref

19. Letouvet B, Arvieux C, Leroy H, Polard JL, Chapplain JM, Common H, Ecoffey C, Huten D, Jolivet-Gougeon A, Tattevin P. Predictors of failure for prosthetic joint infections treated with debridement. Med Mal Infect 2016;46(1):39-43. Crossref

20. Grossi O, Asseray N, Bourigault C, Corvec S, Valette M, Navas D, Djeukou LH, Touchais S, Bémer P, Boutoille D. Gram-negative prosthetic joint infections managed according to a multidisciplinary standardized approach: risk factors for failure and outcome with and without fluoroquinolones. J Antimicrob Chemother 2016;71(9):2593-7. Crossref

21. Lowik CAM, Jutte PC, Tornero E, Ploegmakers JJW, Knobben BAS, de Vries AJ, Zijlstra WP, Dijkstra B, Soriano A, Wouthuyzen-Bakker M. Predicting Failure in Early Acute Prosthetic Joint Infection Treated with Debridement, Antibiotics, and Implant Retention: External Validation of the KLIC Score. J Arthroplasty 2018;33(8):2582-7. Crossref

22. Tornero E, Morata L, Martinez-Pastor JC, Bori G, Climent C, García-Velez DM, García-Ramiro S, Bosch J, Mensa J, Soriano A. KLIC-score for predicting early failure in prosthetic joint infections treated with debridement, implant retention and antibiotics. Clin Microbiol Infect 2015;21(8):786. Crossref

23. Zaruta DA, Qiu B, Liu AY, Ricciardi BF. Indications and Guidelines for Debridement and Implant Retention for Periprosthetic Hip and Knee Infection. Curr Rev Musculoskelet Med 2018;11(3):347-56. Crossref

24. Choi HR, von Knoch F, Zurakowski D, Nelson SB, Malchau $\mathrm{H}$. Can implant retention be recommended for treatment of infected TKA? Clin Orthop Relat Res 2011;469(4):961-9. Crossref

25. Haasper C, Buttaro M, Hozack W. Irrigation and debridement. J Orthop Res 2014;32(Suppl 1):S130-5. Crossref

26. Sherrell JC, Fehring TK, Odum S, Odum S, Hansen E, Zmistowski B, Dennos A, Kalore N; the Periprosthetic Infection Consortium. The Chitranjan Ranawat Award: fate of two-stage reimplantation after failed irrigation and debridement for periprosthetic knee infection. Clin Orthop Relat Res 2011;469(1):18-25. Crossref

27. Koyonos L, Zmistowski B, Della Valle CJ, Parvizi J. Infection control rate of irrigation and debridement for periprosthetic joint infection. Clin Orthop Relat Res 2011;469(11):3043-8. Crossref

28. Jiranek WA, Waligora AC, Hess SR, Golladay GL. Surgical Treatment of Prosthetic Joint Infections of the Hip and Knee: Changing Paradigms? J Arthroplasty 2015;30(6):912-8. Crossref

29. Alijanipour P, Karam J, Llinas A, Vince KG, Zalavras C. Operative environment. J Orthop Res 2014;32(Suppl 1):S6080. Crossref

30. Romano CL, Manzi G, Logoluso N, Romanò D. Value of debridement and irrigation for the treatment of peri-prosthetic infections. A systematic review. Hip Int 2012;22(Suppl 8):S19-24. Crossref

31. Byren I, Bejon P, Atkins BL, Angus B, Masters S, Smith PM, Gundle R, Berendt A. One hundred and twelve infected arthroplasties treated with 'DAiR'(debridement, antibiotics and implant retention): antibiotic duration and outcome. J Antimicrob Chemother 2009;63(6):1264-71. Crossref

32. Gardner J, Gioe TJ and Tatman P. Can this prosthesis be saved?: implant salvage attempts in infected primary TKA. Clin Orthop Relat Res 2011;469(4):970-6. Crossref 
33. Brimmo O, Ramanathan D, Schiltz NK, Pillai ALPC, Klika AK, Barsoum WK. Irrigation and Debridement Before a 2-Stage Revision Total Knee Arthroplasty Does Not Increase Risk of Failure. J Arthroplasty 2016;31(2):461-4. Crossref

34. Nodzo SR, Boyle KK, Nocon AA, Henry MW, Mayman DJ, Westrich GH. The Influence of a Failed Irrigation and Debridement on the Outcomes of a Subsequent 2-Stage Revision Knee Arthroplasty. J Arthroplasty 2017;32(8):250812. Crossref

35. Kim K, Zhu M, Cavadino A, Munro JT, Young SW. Failed Debridement and Implant Retention Does Not Compromise the Success of Subsequent Staged Revision in Infected Total Knee Arthroplasty. J Arthroplasty 2019;34(6):1214-20. Crossref

36. Haddad FS, Sukeik M, Alazzawi S. Is single-stage revision according to a strict protocol effective in treatment of chronic knee arthroplasty infections? Clin Orthop Relat Res 2015;473(1):8-14. Crossref

37. Castellani L, Daneman N, Mubareka S, Jenkinson R. Factors Associated with Choice and Success of One- Versus Two-Stage Revision Arthroplasty for Infected Hip and Knee Prostheses. HSS J 2017;13(3):224-31. Crossref

38. Silva M, Tharani R, Schmalzried TP. Results of direct exchange or debridement of the infected total knee arthroplasty. Clin Orthop Relat Res 2002;404:125-31. Crossref

39. Bialecki J, Bucsi L, Fernando N, Foguet P, Guo S, Haddad F, Hansen E, Janvari K, Jones S, Keogh P, McHale S, Molloy R, Mont MA, Morgan-Jones R, Ohlmeier M, Saldaña A, Sodhi N, Toms A, Walker R, Zahar A. Hip and Knee Section, Treatment, One Stage Exchange: Proceedings of International Consensus on Orthopedic Infections. J Arthroplasty 2019;34(2):S421-6. Crossref
40. Goksan SB, Freeman MA. One-stage reimplantation for infected total knee arthroplasty. J Bone Joint Surg Br 1992;74$\mathrm{B}(1): 78-82$. Crossref

41. Tibrewal S, Malagelada F, Jeyaseelan L, Posch F, Scott G. Single-stage revision for the infected total knee replacement: results from a single centre. Bone Joint J 2014;96-B(6):75964. Crossref

42. Gehrke T, Zahar A, Kendoff D. One-stage exchange: it all began here. Bone Joint J 2013;95-B(11_Supple_A):77-83. Crossref

43. Nagra NS, Hamilton TW, Ganatra S, Murray DW, Pandit H. One-stage versus two-stage exchange arthroplasty for infected total knee arthroplasty: a systematic review. Knee Surg Sports Traumatol Arthrosc 2016;24(10):3106-14. Crossref

44. Kunutsor SK, Whitehouse MR, Blom AW, Beswick AD; INFORM Team. Re-Infection Outcomes following One- and Two-Stage Surgical Revision of Infected Hip Prosthesis: A Systematic Review and Meta-Analysis. PLoS One 2015;10(9):e0139166. Crossref

45. Kunutsor SK, Whitehouse MR, Lenguerrand E, Blom AW, Beswick AD; INFORM Team. Re-Infection Outcomes Following One- And Two-Stage Surgical Revision of Infected Knee Prosthesis: A Systematic Review and Meta-Analysis. PLoS One 2016;11(3):e0151537. Crossref 